\title{
EL PALACIO DE RUY LÓPEZ DÁVALOS Y SUS BOCETOS INÉDITOS EN LA SINAGOGA DEL TRÁNSITO: ESTUDIO DE SUS YESERÍAS EN EL CONTEXTO ARTÍSTICO DE 1361 (II)*
}

\author{
Carmen Rallo GruSS \\ Juan Carlos RuIz SouzA \\ Universidad Complutense \\ Universidad Autónoma de Madrid
}

\begin{abstract}
ADDENDA
LA TÉCNICA DE LA YESERÍA HISPANOMUSULMANA Y EL EJEMPLO DEL PALACIO DE RUY LÓPEZ DÁvAlOS
\end{abstract}

El arte hispanomusulmán se caracteriza por el uso de innumerables técnicas artísticas distintas: estuco, piedra, mosaico, cerámica, madera, marfil, etc., y aún por algo más significativo como es la transferencia de los efectos de una técnica a otra, resultando un todo ornamental difícil de estudiar por separado. Así, ante los personajes de la ornamentación del Palacio de Suero Téllez no se puede evitar la imagen de los marfiles musulmanes, como la arqueta de Leyre (en el Museo de Navarra) donde el soberano se nos muestra sentado dentro de una mandorla circular, o la composición de telas musulmanas como las del monasterio de Oña o las del museo de las Huelgas de Burgos.

Para definir la técnica en que está realizada la ornamentación del Palacio de Suero Téllez, se suele utilizar el término «estuco», término muy controvertido por las diferentes acepciones en que se ha empleado. En la Antigüedad se ha hablado de un «estuco romano», elaborado con cal y polvo de mármol ${ }^{1}$, que presentaba un cierto grado de brillo.

En la Edad Media, acerca de los «estucos musulmanes», Grabar nos dice: Su utilización como técnica arquitectónica no es nueva..., se conocía (su uso) en el Mediterráneo, pero al parecer se empleaba principalmente para usos secundarios, como reparaciones o terminaciones rápidas de trabajos inacabados... Una de las principales consecuencias del equilibrio introducido por el Islam entre las distintas regiones fue la propagación rápida y repentina del estuco desde el Iraq y el Irán a todo el mundo musulmán ${ }^{2}$. Volveremos al tema de ese «estuco musulmán» más adelante.

* El presente artículo, además de completar el trabajo publicado en el número anterior ( $\mathrm{Al}$ Qantara, XX [1999], pp. 275-297), presenta las fotografías que en él eran aludidas.

${ }^{1}$ Vitrubio, Los diez libros de la Arquitectura, reproducción facsímil de la ed. de la Imprenta Real de 1787. Barcelona, 1987. Libro VII, cap. III: «Estucado de las bóvedas:... con un mortero de cal y arena y, por último, se le dará el pulimento con una composición de mármol pulverizado... No se puede emplear en ellas el yeso, sino que hay que hacerlas con una pasta de cal y mármol pulverizado".

${ }^{2}$ Grabar, O., La formación del Arte Islámico, Madrid, 1981 (1. a edic. Yale, 1973), p. 217. Sin embargo, desconoce las realizaciones romanas de gran calidad como la decoración de las termas de Herculano. Eso sí, estos estucos, de los que pocos nos han llegado a nuestros días, estaban realizados, como Vitrubio comentaba, con cal y polvo de mármol, técnica muy laboriosa y, por tanto, costosa. 
Siguiendo con la historia del estuco, éste fue redescubierto en el Renacimiento en el Palacio de Tito. Vasari atribuye a Juan de Udine la «reinvención» de este tipo de «stucco lustro», aplicándolo a la decoración de las logias de Rafael que «... le mandó hacer, con gran alegría, todos los techos con estuco, con bellísimos adornos y grutescos como los antiguos» ${ }^{3}$. No solamente se aplica el término «estuco» a esas decoraciones en relieve, sino por extensión, a toda superficie mural decorada con un acabado satinado y una dureza superficial característicos.

Más adelante, para lograr el deseado resultado final, se van a utilizar diferentes materiales y técnicas, ya sean mezclas de cal y yeso, cal y árido ${ }^{4}$ como en el caso del romano clásico, yeso y cola, acabados a la cera, al aceite, revocos planchados con calor, etc., lo que provocaría en el siglo XIX una gran abundancia de manuales sobre recetas de hacer estucos ${ }^{5}$. Todo ello causa la confusión del término en su utilización actual, que significa (erróneamente) más un acabado especial del revestimiento de las paredes, que la identificación con unos materiales o unas técnicas.

No siempre ha ocurrido así, y Juan de Villanueva en su Arte de la Albañilería ${ }^{6}$ nos dice: «Muchas son las mezclas y composiciones que se hacen con la cal y el yeso para los blanqueos y guarniciones de molduras, ya sea para lograr su mayor blancura, permanencia, lustre o pulimento. A las unas mezclas llámanse siendo yeso, yeserías; de cal, estucos; y de la mezcla de unos y otros en ciertas dosis y composiciones se forma la escayola colorida, con la que se imitan los mármoles».

Siguiendo a este arquitecto, por tanto, y por pura semántica, no se puede denominar «estuco» a la ornamentación en relieve realizada por los hispanomusulmanes en yeso, sino yeserías.

Se atribuye en una leyenda el descubrimiento de la utilización del yeso a un pastor de Montmartre (París) que habiendo utilizado piedras de yeso como

\footnotetext{
${ }^{3}$ Vasari, Les vies des plus excellents peintres, sculpteurs et architectes (1550), Buenos Aires, 1945, apud Bruquetas, R., «El trabajo de la yesería en España», en La obra de yeso policromado de los Corral de Villalpando, Madrid, 1994, p. 79.

${ }^{4}$ Se llama «árido» a aquella materia constituyente del mortero que, en principio, es inerte, es decir, ni oficia como aglutinante ni como reactivo. Frecuentemente la denominación de «árido», engloba cualquier tipo de arena o minerales en forma pulverulenta.

${ }^{5}$ Sáenz y García, M., Manual del pintor, dorador y charolista, Madrid, 1872; Díez, R. P., «Arte de hacer estuco jaspeado, o de imitar jaspes a poca costa, y con mayor propiedad (1785)», Archivo Español de Arte y Arqueología (1932), pp. 243-247; Fornés y Gurrea, M., Observaciones sobre la práctica de edificar, Valencia, 1841; Palomino, A., El Arte pictórico y la escala óptica, Madrid, 1797; Lade, K. y Winckler, A., Yesería y estuco, Madrid, 1960, etc. Algunos de ellos comentados en Gárate, I., El arte de la cal, Madrid, 1994, pp. 185-208.

${ }^{6}$ Villanueva, J., Arte de la albañilería, ed. facsímil de la ed. de F. Martínez 1827, Madrid, 1977, p. 81
} 
hogar al aire libre para calentar sus alimentos, observó que bajo el efecto de un oportuno chaparrón las piedras tomaron cuerpo, solidificándose alrededor de los tizones apagados del fuego ${ }^{7}$.

En la Edad Antigua ya era muy apreciado por los romanos el yeso fibroso que se obtenía en España, llamado «de espejuelo», de excelente calidad y extraordinaria blancura ${ }^{8}$.

En Siria y Egipto, a partir del siglo viII va a tener gran éxito la técnica del yeso, cuando se inicia la técnica de la talla a bisel y el vaciado ${ }^{9}$; desde allí va a ser expandida por todo el mundo musulmán en su paso de conquista: los extensos nuevos programas de construcción requerían medios rápidos de edificación y decoración, con materiales de fácil obtención y manejo. La flexibilidad de este material les permitía utilizarlo tanto en escultura como para la reparación de un capitel reutilizado. Con él se podían experimentar diseños recién importados o continuar tradiciones locales, transformar la arquitectura de los edificios de un modo barato y adaptable, y sobre todo, permitía desarrollar un arte de ilusión que podía hacer parecer las cosas de distinta forma a su realidad.

El trabajo en yeso tuvo gran perduración durante la Edad Media no sólo en la zona islámica, sino también en la cristiana. Ello se debe en gran parte a la seducción que ejercieron las mansiones musulmanas sobre los reyes conquistadores y, a su semejanza, su corte; la importación de objetos y decoración de alAndalus, o la imitación de lo remanente en los lugares conquistados, era la máxima expresión de lujo y gusto refinado.

Diversos textos españoles de la Edad Media nos hablan de este material: san Isidoro en las Etimologías ${ }^{10}$ o El Lapidario, de Alonso X ${ }^{11}$ que caracteriza la

${ }^{7}$ Costes, J., Manual del yesero y del estucador, Barcelona, 1966, p. 9.

8 Plinio «El Viejo», Historia Natural, L. XXVI, Edic. de la Universidad Nacional Autónoma de México, 1976, vol. III, cap. XXII, p. 684. Plinio localiza la piedra «especular» en la España Citerior. Ese tipo de piedra es interpretado por Villanueva como el «yeso de espejuelo», variedad de alabastro de la que se obtiene yeso de extraordinaria blancura. Sin duda Plinio, en su disertación, se refiere a él, pero mezclando su descripción con roca calcárea, en algún caso: «pero por la mayor parte es de naturaleza fósil» (en este caso se trataría de espato de Islandia, calcita), "... cayendo las fieras en semejantes pozos, las médulas de sus huesos se convierten también en la misma naturaleza de piedra» (aquí se está refiriendo a una carbonatación, es decir, a una roca calcárea), etc. Sin embargo, en la mayoría de los casos sí se refiere sin lugar a dudas al yeso: "para henderse por qualquiera parte en sutilísimas láminas», por ejemplo. Los errores de Plinio están basados en que su método no es científico como en la actualidad, sino descriptivo, y se basa en la apariencia de las distintas rocas.

${ }^{9}$ Bruquetas, R., op. cit., 1994, p. 80.

${ }^{10}$ San Isidoro, Etimologías, Francisci Lorenzanae, 1801 (versión latina comentada), Toledo. Libro XIX, cap. X, punto 21: «Gypsum cogantum calci est, et est graecum nomen. Plura eius genera. Omnium autem optimum e lapide speculari. Est enim in signis aedificiorum, et coronis gratissimis» (se ha utilizado la edición impresa y comentada por Francisci Lorenzanae de 1801, el cardenal Lorenzana).

" Alfonso X, El Lapidario, texto de Brey, M., Valencia, 1968, p. 27. 
piedra de yeso como «... cuando es molida y mezclada con alguna cosa, endurece luego y hácese piedra, por lo que la meten los físicos mucho en las medicinas que son secantes; también es buena para labores de casas y de otras cosas porque las hacen con ella sutiles y muy buenas».

La gran importancia que alcanza este material, ya para la construcción, ya para la ornamentación, queda patente al ser mencionado en distintos puntos de las Cortes de Valladolid de Pedro I de 1351, en relación con varias zonas de España. Precisamente el arzobispado de Toledo ${ }^{12}$ regula los precios distinguiendo entre «yeso pardo por majar» (en piedra, sin machacar), que valdría siete maravedíes el «caffiz» ${ }^{13}$ y el yeso blanco, a cuatro dineros la arroba; destacándose la calidad especial del «yeso de Toledo».

Asimismo, las Cortes de Toro de 1369 de Enrique II ${ }^{14}$ dedican su atención al yeso, fijando el precio de la fanega de yeso cernido (seleccionado según tamaño mediante un cedazo) en un maravedí, y la por cerner, en seis dineros.

El yeso ${ }^{15}$ se presenta en la naturaleza como sulfato cálcico bihidrato, cristalizado en forma pétrea, que al calentarse en hornos a diferentes temperaturas, según las propiedades que queramos obtener, se convierte en hemi-hidrato (a partir de $120^{\circ} \mathrm{C}$ ). $\mathrm{Al}$ amasarlo con agua se obtiene una masa de gran viscosidad, plástica, fácil de trabajar e incluso de moldear, de notable adhesividad, resistente al fuego y baja conductividad del frío y el calor (propiedades aislantes), que endurece al recristalizarse. Para este endurecimiento no es necesario más que el agua de absorción del amasado, por lo que los morteros de yeso se pueden calificar de anaerobios, es decir, que no necesitan del aire para su fraguado. En resumen, tanto su proceso de fabricación, en hornos de fácil construcción, incluso tradicionalmente en simples marmitas, como su utilización en morteros, no ofrece ninguna complejidad ${ }^{16}$.

En sentido contrario podemos calificar su conservación. Los cambios de humedad en el ambiente le afectan profundamente: el sulfato cálcico, ávido de agua, en medio húmedo capta la del aire circundante, se hincha y rompe;

\footnotetext{
12 Colmeiro, M., Cortes de los Antiguos Reinos de Castilla y León, Madrid, 1883, cap. III, p. 80: «15. ... Et que den por el caffiz del yesso pardo por majar, aqual quier quelo vendiere, a ssiete $\mathrm{mr}$; et que den por la arrova del yesso blanco, aqual quier quelo vendiere, aquatro dineros. Et este preçio dela cal et del yesso que ssea en Toledo, puesto ay et traydo et medido, assegund dicho es, en la casa del quelo comprare...».

${ }^{13}$ Según el Diccionario de Autoridades, Madrid, ed. de 1976, el «caffiz» es una medida que varía según el lugar: «... en unas partes hace doce fanegas, en otras seis y en otras más...».

${ }^{14}$ Colmeiro, M., op. cit., p. 179.

${ }^{15} \mathrm{El}$ término gypsum es griego, los árabes lo denominan al-ŷișs, que en el castellano antiguo deviene en algez.

16 Para ampliar el conocimiento del yeso como material, el manual más completo es el de Turco, T., Il Gesso: lavorazione, trasformazione, imphiegi, Milán, 1988.
} 
si sucede al contrario, en ambiente muy seco, cede agua al aire, convirtiéndose en un material mucho más blando, que se disgrega con facilidad.

El yeso no tiene poder aglutinante de pigmentos, aunque sí de adhesión frente a otros materiales. Por ello, para poder pintar sobre un relieve realizado en yeso, es necesario mezclar los pigmentos con un vehículo adherente, sea cola, caseína, goma, etc. Es la técnica de la pintura al temple.

Quizá el mayor problema que se presentaba al autor de las yeserías hispanomusulmanas era el tiempo en que debía realizarse el relieve, que dependía íntimamente del tiempo de fraguado del yeso. El tiempo de fraguado de un yeso viene condicionado por su calidad (que proviene de la calidad de su piedra de origen y de una adecuada cocción), de la cantidad de agua añadida en el amasado, y de cómo se realizara éste. Pero además, se conocían otra serie de recursos para acelerar o retardar el tiempo de fraguado, según utilizaran un método de moldeo o de esculpido. Como ejemplos de aditivos conocidos tradicionalmente podemos nombrar la cola, la albúmina, el carbonato cálcico, el amoníaco, que retardan el fraguado; la sal común, en una proporción menor al 6 por 100, lo acelera ${ }^{17}$.

Para lograr el efecto de relieve de una yesería no se utilizaba un solo estrato de yeso, sino varios. De hecho, en el relieve de los paramentos de Suero Téllez podemos descubrir hasta cuatro estratos diferentes. Cuatro también tienen las yeserías de la Sinagoga del Tránsito ${ }^{18}$, con las que tantos paralelismos guarda. La capa interna, que es la que se utilizaba para encubrir las desigualdades del muro, era una capa gruesa, de varios centímetros de espesor, de grano basto, cuya composición tiene, además de yeso negro, sílice y arcillas ${ }^{19}$. Las dos superiores, compuestas solamente con yeso y una adición proteínica, seguramente debidas a un aporte de cola animal en pequeña proporción (que además de reforzar su resistencia, retardaría el fraguado), eran el objeto de la decoración en relieve ${ }^{20}$. Trabajadas formando placas ${ }^{21}$, estaban sujetas al muro

17 Turco, T., op. cit., pp. 32-45.

18 Rallo, C., «Restauración de las yeserías de la sala de las mujeres en la sinagoga del Tránsito», Sefarad XLIX (1989), pp. 397-406.

${ }^{19}$ Los exámenes analíticos se han realizado en el laboratorio de química de la Universidad Alfonso X; se ha efectuado una difractometría por infrarrojos.

${ }^{20}$ Saladin, H., L'Alhambre et Grenade, París, 1974, p. 5 nos lo describe: «... sur une surface enduite de plâtre, l'ouvrier traçait à la pointe sèche le dessin projeté; ensuite, à l'aide de ciseaux et de burins, il découpait dans le plâtre frais les ornaments dont il avait fait le croquis. Ce procédé exigeait l'emploi de plâtre à prise lente, qu'on peut obtenir en ajoutant au plâtre de la colle ou du sel, comme le font actuellement les ouvriers tunisiens...».

21 Esta técnica de placas ya fue señalada por Marçais, G., L'architecture musulmane d'Occident, París, 1954, pp. 228-229: «A l'intérieur de la Kotoubiya de Marrakech, des panneaux demeurés en cours d'éxécution (?) nous font connaître la technique des gysoplasters et la préparation de leur travail...». 
gracias al fraguado de la capa de yeso intermedia, colocada en último lugar, una vez las placas estaban ya esculpidas.

El color, en clara servidumbre respecto al relieve para ayudar al juego de luces y sombras que el artífice deseaba, no se localizaba aleatoriamente, teniendo policromía los temas de cierta importancia: las flores, los pájaros, las figuras. El tallo vegetal se define con una línea negra que va subrayando la geometría curva de la composición y ciertas zonas planas que actúan de fondo para otras formas más elaboradas se colorean en rojo, verde o negro. Los pigmentos, preparados a partir de tierras naturales (óxidos de hierro para el verde, el ocre y el rojo), humo de carbón para el negro y azurita para el azul, están aglutinados con cola animal, casi desaparecida por el paso del tiempo.

\title{
RESUMEN
}

La «yesería» constituye uno de los elementos decorativos más característicos de nuestra arquitectura medieval. La imagen que hoy tenemos de La Alhambra, de la Sinagoga del Tránsito, y de tantos otros palacios y conventos, se debe a ese barato elemento constructivo que logró crear la misma apariencia de lujo de las telas o el marfil. Como hemos podido estudiar en nuestro artículo del número anterior (Al-Qanțara, XX, 275-297), en el palacio de Ruy López Dávalos de Toledo se conserva uno de los conjuntos más fascinantes del siglo XIV, el cual nos ha llevado a preparar estas páginas sobre la técnica de la yesería medieval.

\begin{abstract}
Corned stucco represents one of the most characteristic elements of Spanish medieval architecture. The image that we have of the Alhambra, of Samuel Halevi's synagoge —el Tránsito - and of countless other palaces and monasteries is due to this cheap construction material which could imitate the luxurious quality of silk textiles and ivories. In our previous article (Al-Qanțara, XX, 275-97), we showed that Ruy López Dávalos de Toledo's palace conserves an important group of carved stuccos. In this paper, we discuss its technique of fabrication.
\end{abstract}




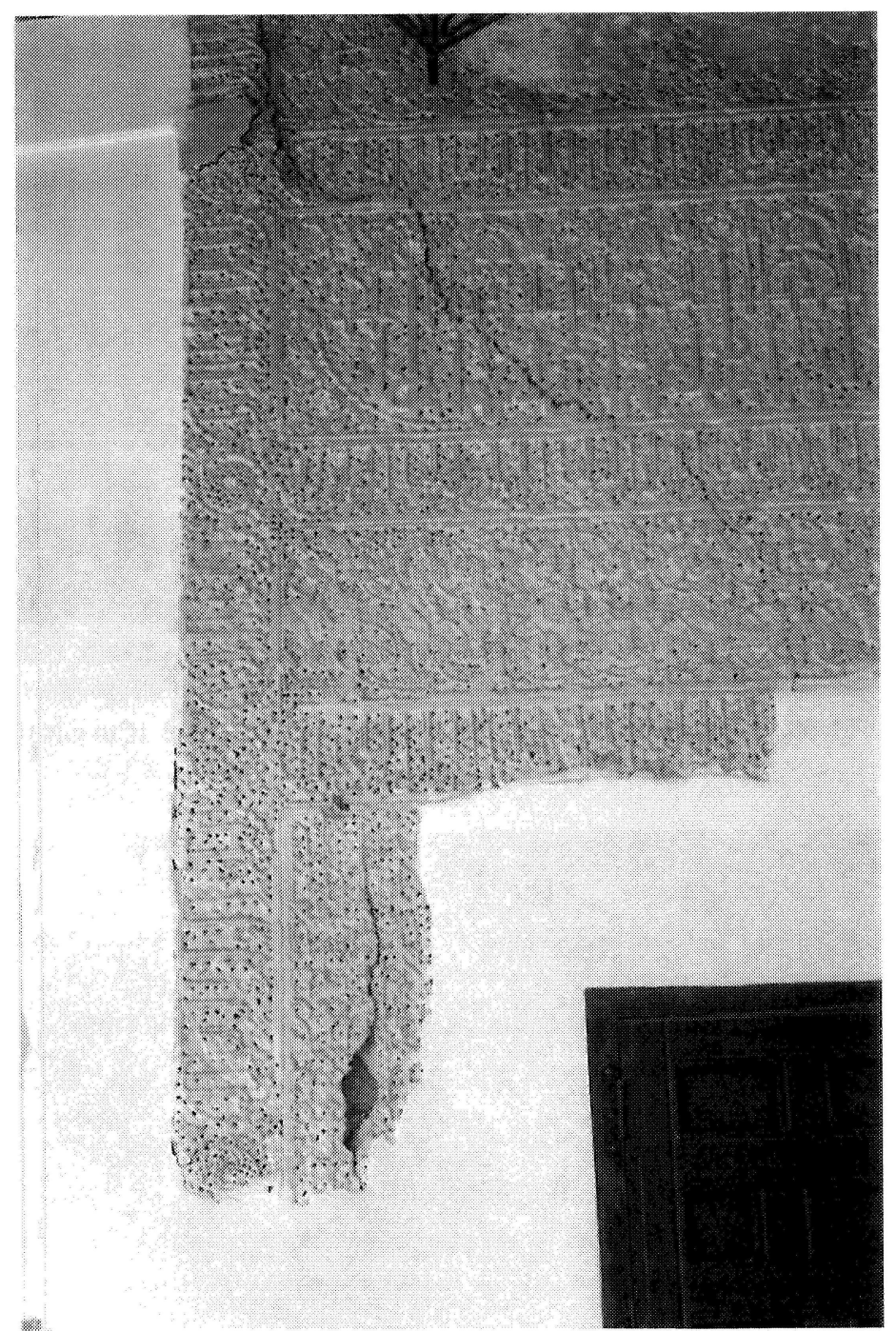

Lám. 1: Cara interna de la portada que se encuentra en el extremo norte de la panda occidental del claustro del seminario. (Croquis A.) 


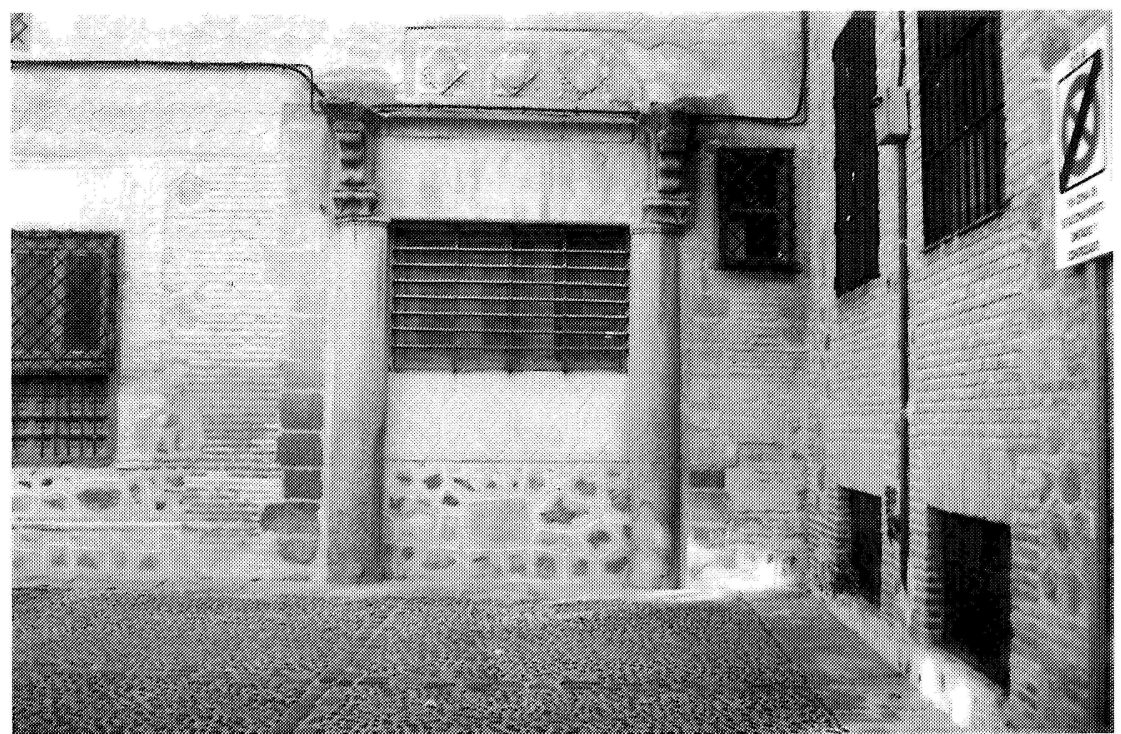

Lám. 2: Portada exterior que da a la plaza de Santa Isabel. (Croquis B.)

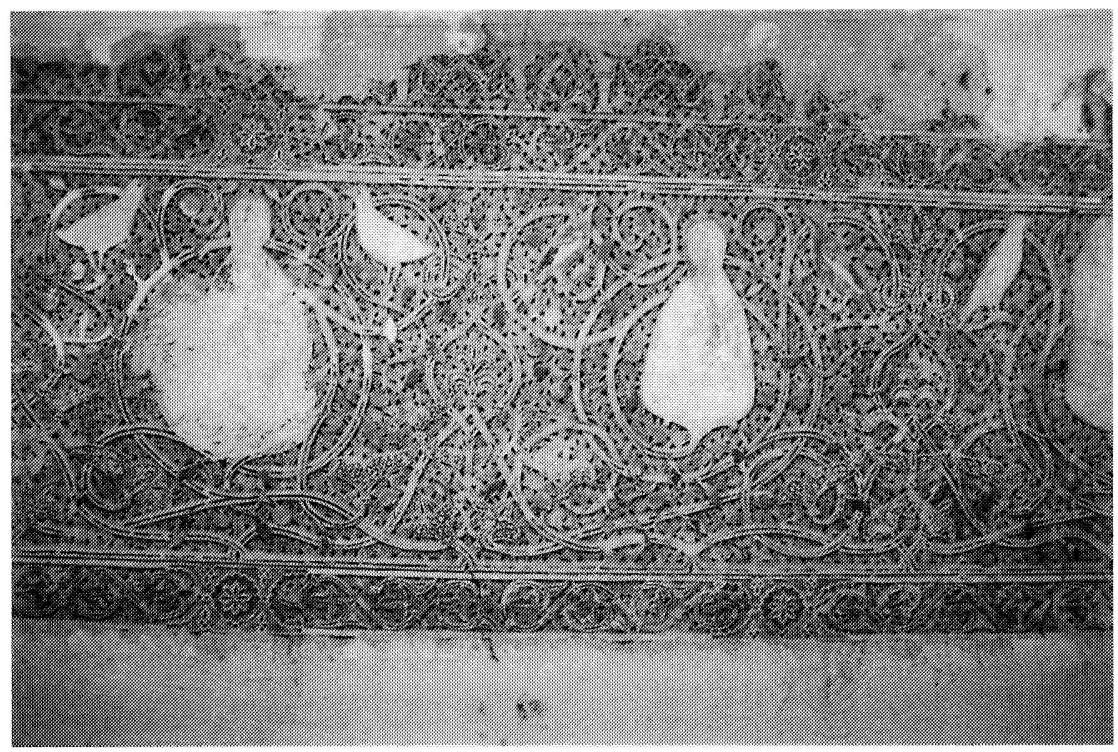

Lám. 3: Vista general del friso de yeserías de la parte-superior de la alcoba occidental del palacio. Paramento norte. Hoy en el segundo piso. (Croquis C.) 


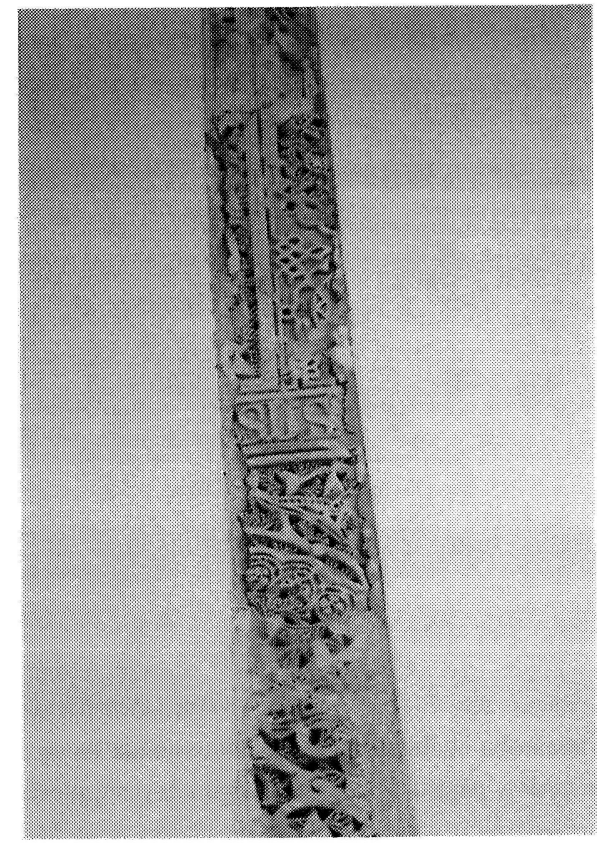

Lám. 4: Testigo vertical en el muro norte del salón central del palacio. (Croquis D.)

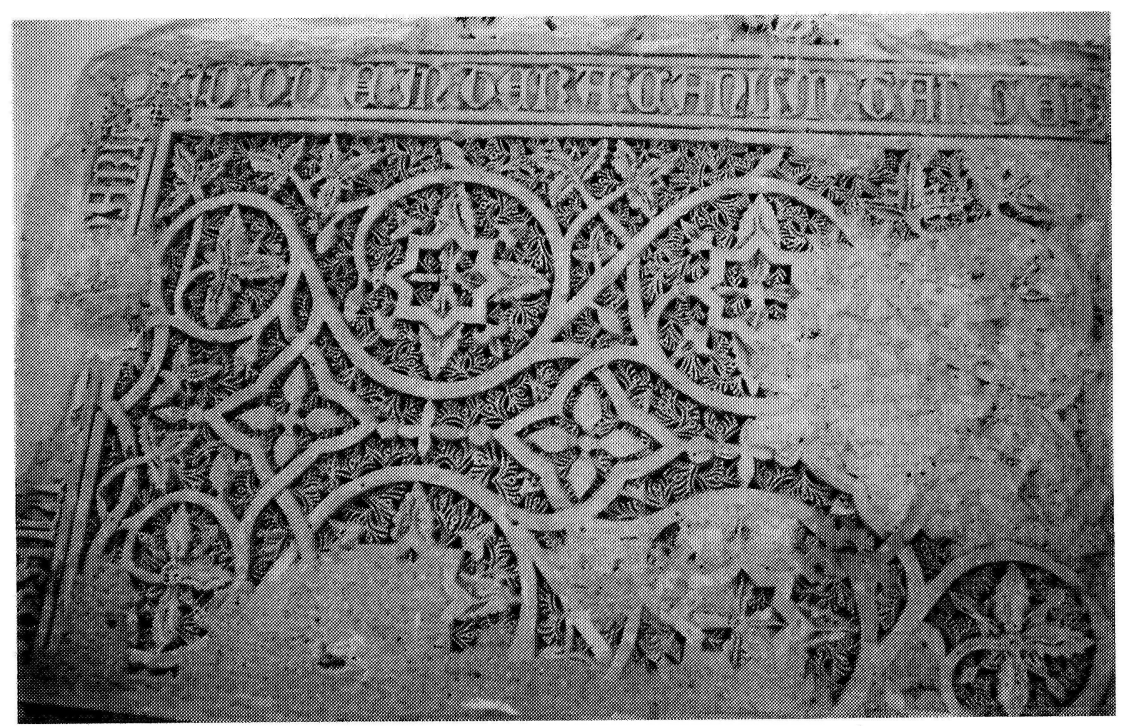

Lám. 5: Yesería que flanquearía la puerta que daba acceso desde el salón central del palacio a la alcoba occidental del mismo. (Croquis E.) 


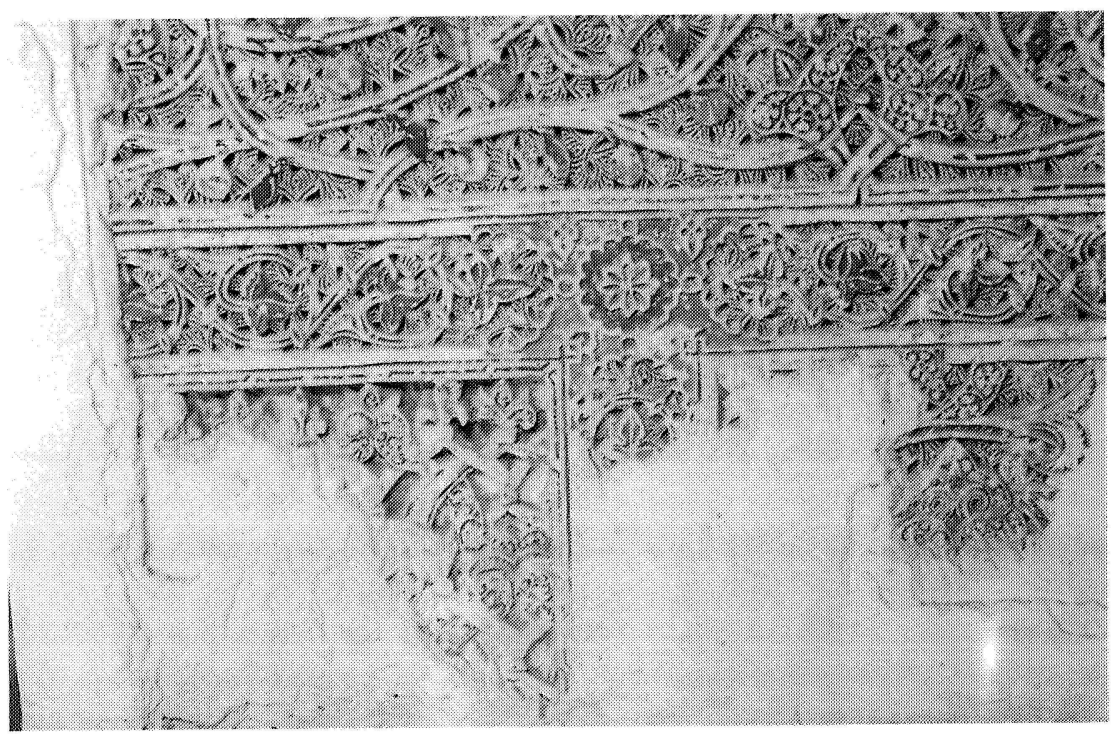

Lám. 6: Yesería de la alcoba occidental del palacio, situada en su muro oriental, justo debajo del friso de personas y pájaros. Hoy en el segundo piso, junto al suelo. (Croquis F.)

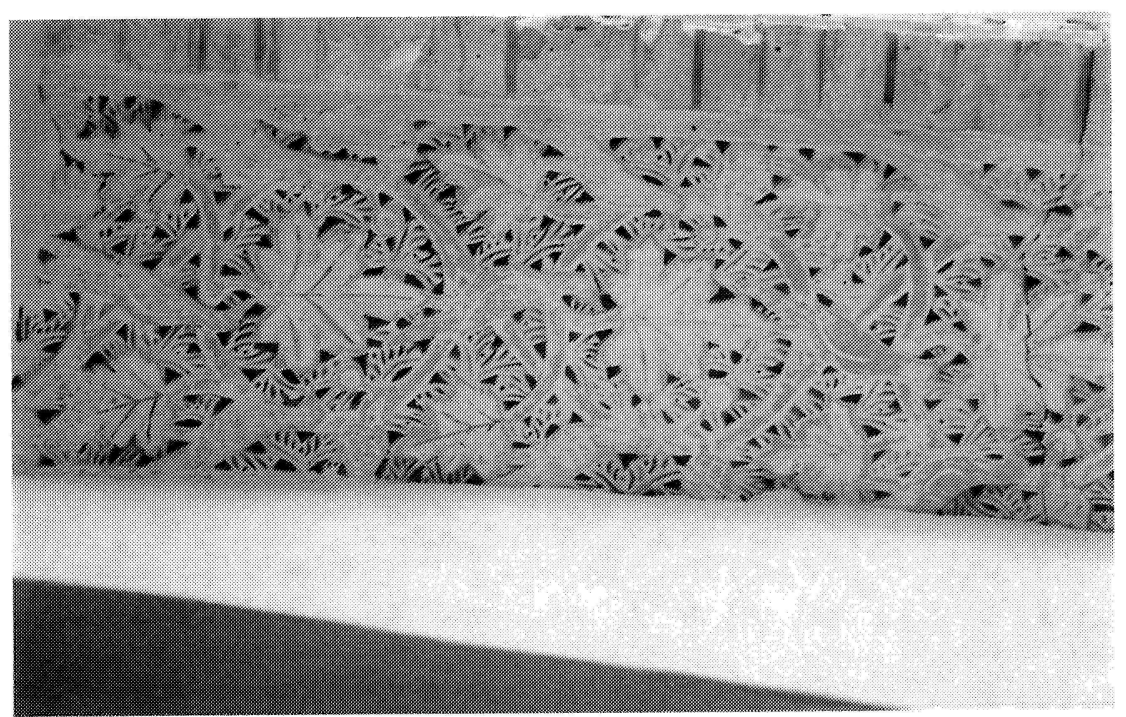

Lám. 7: Intradós del arco de los pájaros del Patio de los Naranjos del convento de Santa Isabel de los Reyes de Toledo. 


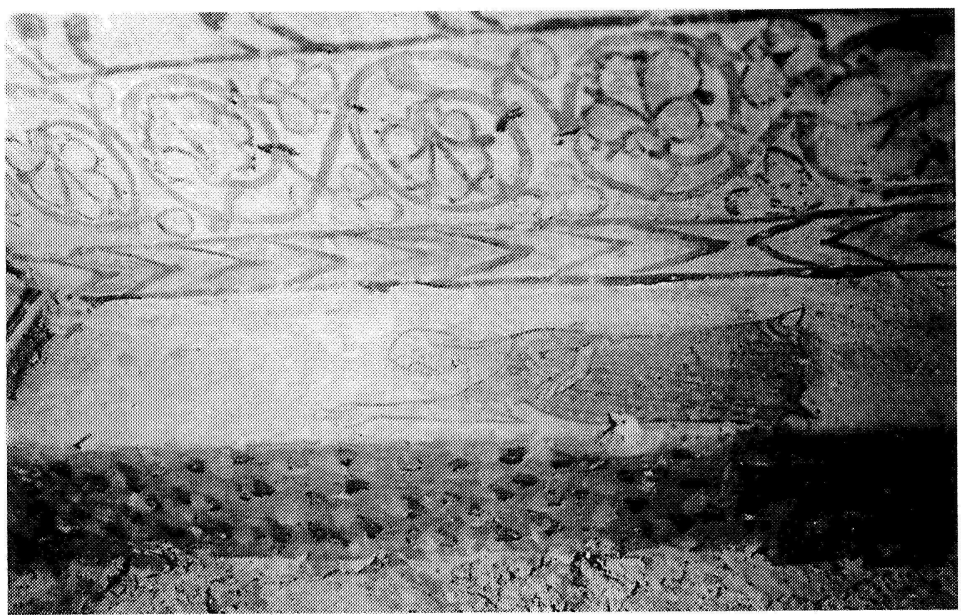

Lám. 8: Boceto inédito de la Sinagoga del Tránsito.

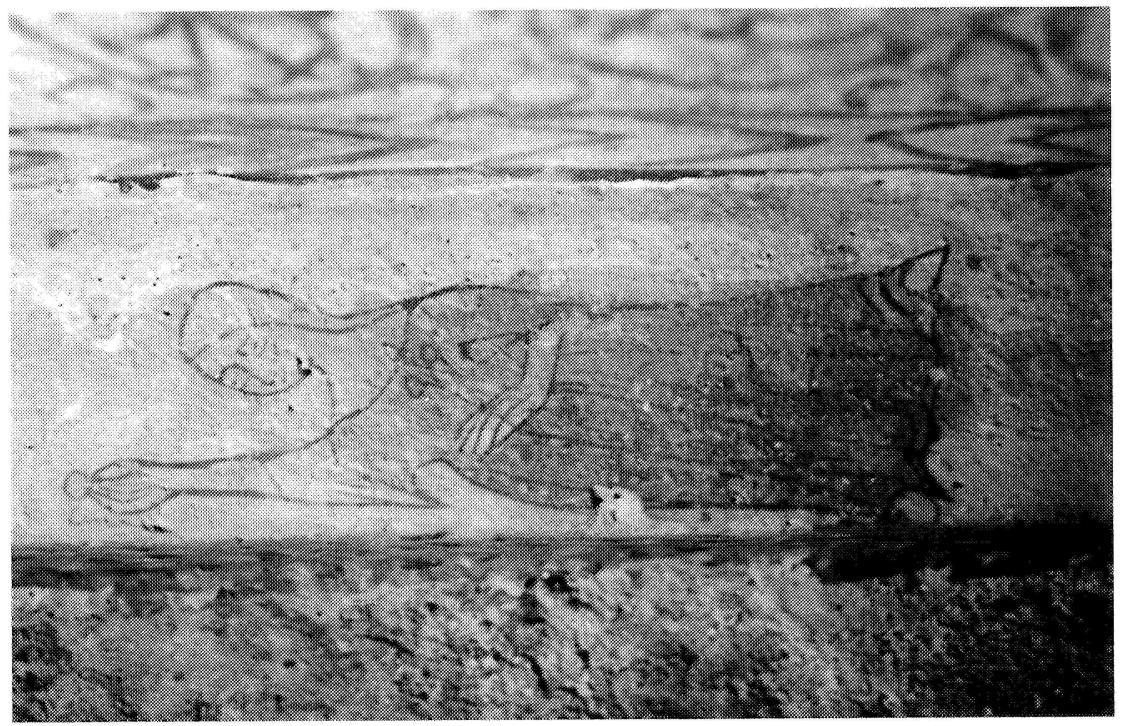

Lám. 9: Boceto inédito de la Sinagoga del Tránsito. Detalle. 


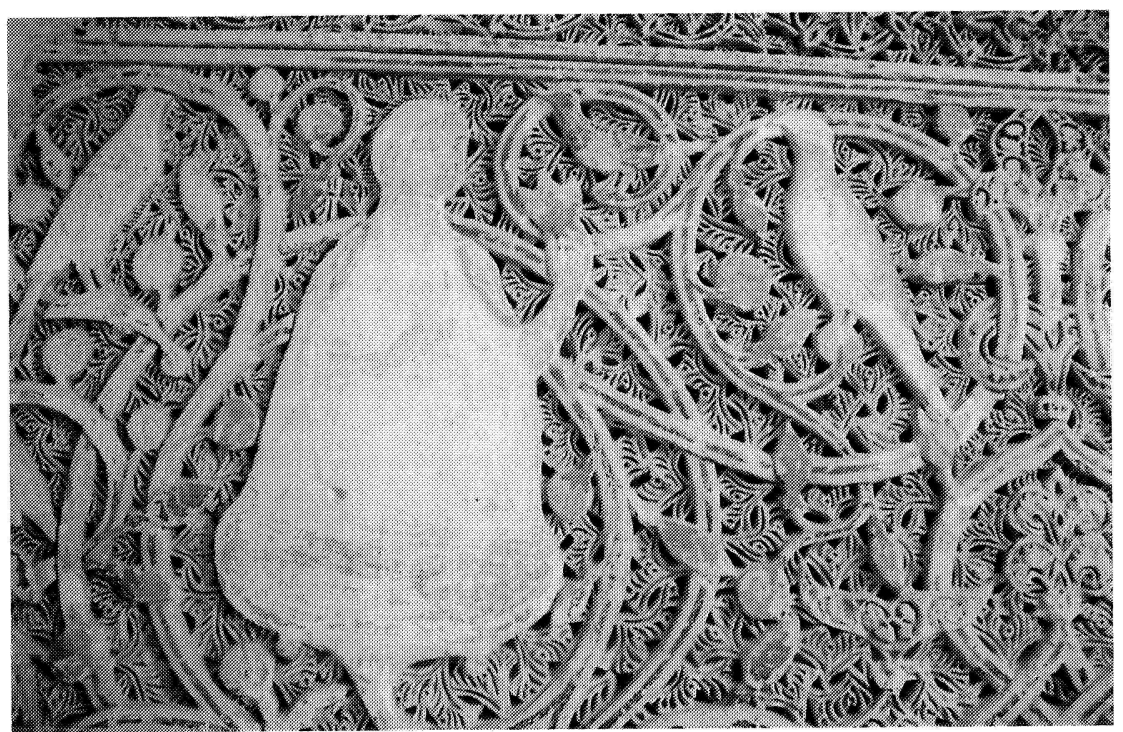

Lám. 10: Mujer y pájaros del friso superior de la alcoba occidental, muro meridional. Hoy en el segundo piso. (Croquis G.) 